\title{
Impact of body mass index on outcomes in patients undergoing transfemoral transcatheter aortic valve implantation
}

Astrid C. van Nieuwkerk, MD, ${ }^{a}$ Raquel B. Santos, MD, ${ }^{\mathrm{a}, \mathrm{b}}$ Samantha Sartori, $\mathrm{PhD},{ }^{\mathrm{c}}$ Ander Regueiro, MD, Didier Tchétché, $\mathrm{MD},{ }^{\mathrm{e}}$ Roxana Mehran, $\mathrm{MD},{ }^{\mathrm{c}}$ and Ronak Delewi, MD, PhD, ${ }^{\mathrm{a}}$ the CENTER collaboration*

\section{ABSTRACT}

Objective: This study sought to investigate the effect of body mass index on outcomes in patients with severe aortic valve stenosis undergoing transcatheter aortic valve implantation.

Methods: A total of 12,381 patients undergoing transfemoral transcatheter aortic valve implantation were divided into body mass index categories: underweight $\left(<18.5 \mathrm{~kg} / \mathrm{m}^{2}\right)$, normal weight $\left(18.5-24.9 \mathrm{~kg} / \mathrm{m}^{2}\right)$, overweight $\left(25.0-29.9 \mathrm{~kg} / \mathrm{m}^{2}\right)$, and obesity $\left(>30 \mathrm{~kg} / \mathrm{m}^{2}\right)$. Primary endpoints were differences in 30-day and 1-year allcause mortality. Secondary endpoints included all other clinical endpoints such as stroke. Univariate and multivariate odds ratios were calculated using logistic and cox regression analyses.

Results: Two percent $(n=205)$ of patients were underweight, $29 \%(n=3564)$ were normal weight, $44 \%(n=5460)$ were overweight, and $25 \%(n=3152)$ were obese. Thirty-day mortality was lower in overweight (5.3\%, odds ratio, 0.73 ; $95 \%$ confidence interval, 0.61-0.88; $P=.001)$ and obese patients (5.2\%, odds ratio, $0.74 ; 95 \%$ confidence interval, 0.60-0.92; $P=.006)$, but higher in underweight ( $9.8 \%$, odds ratio, $1.51 ; 95 \%$ confidence interval, $0.92-2.47 ; P=.010$ ) as compared to normal weight patients $(6.9 \%)$. After multivariate adjustment, 30-day mortality was not significantly different across body mass index categories. However, 1-year mortality was higher in underweight patients (hazard ratio, 1.52; 95\% confidence interval, 1.10-2.09; $P=.011)$. Stroke rates were comparable between body mass index groups.

Conclusions: For overweight and obese patients with severe aortic valve stenosis undergoing transcatheter aortic valve implantation, there was no 30-day difference in mortality compared with patients with normal weight. However, underweight patients showed higher rates of 1-year mortality after transcatheter aortic valve implantation. (JTCVS Open 2021;6:26-36)

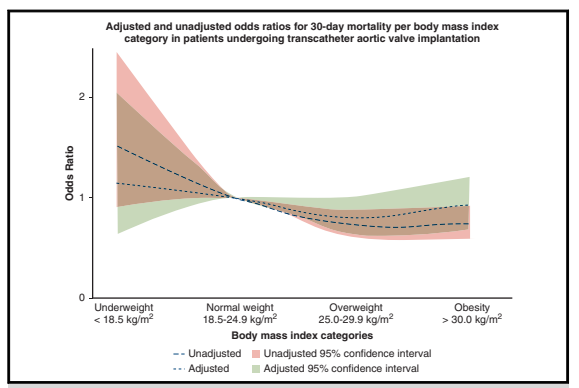

Odds ratios for 30-day mortality per body mass index category in patients undergoing TAVI.

\section{CENTRAL MESSAGE}

Overweight and obese patients

with severe aortic valve stenosis undergoing TAVI showed no 30day difference in mortality as compared to normal weight patients. However, underweight patients had higher rates of 1year mortality.

\section{PERSPECTIVE}

Underweight is an important predictor for 1-year mortality rates after TAVI. This warrants a more thorough assessment of these patients, including adjustments to improve this frailty and a closer follow-up.

See Commentaries on pages 37 and 39.
From the ${ }^{\mathrm{a}} \mathrm{Heart}$ Center, Department of Clinical and Experimental Cardiology, Amsterdam UMC, University of Amsterdam, the Netherlands; ${ }^{b}$ Department of Cardiology, Centro Hospitalar Universit $x E$ 1rio do Porto, Porto, Portugal; ${ }^{\mathrm{c}}$ The Zena and Michael A. Wiener Cardiovascular Institute, Icahn School of Medicine at Mount Sinai, New York, NY; ${ }^{\text {d} S e r v i c i o ~ d e ~ C a r d i o l o g i ́ a, ~ H o s p i t a l ~ C l i ́ n i c, ~ B a r c e l o n a, ~}$ Spain; and ${ }^{\mathrm{e} C l i n i q u e}$ Pasteur, Toulouse, France.

Supported by the Netherlands CardioVascular Research Initiative: the Dutch Heart Foundation (CVON 2018-28 \& 2012-06 Heart Brain Connection), Dutch Federation of University Medical Centers, the Netherlands Organisation for Health Research and Development, and the Royal Netherlands Academy of Sciences. Dr Santos is a grant recipient from the Sociedade Portuguesa de Cardiologia.

Drs van Nieuwkerk and Santos contributed equally to this article.
* Contributing authors from the Cerebrovascular Events in Patients Undergoing Transcatheter Aortic Valve Implantation (CENTER) collaboration are listed in the Acknowledgments.

Received for publication March 17, 2021; accepted for publication March 17, 2021; available ahead of print April 28, 2021.

Address for reprints: Ronak Delewi, MD, PhD, Department of Cardiology, Heart Center, Amsterdam University Medical Center, University of Amsterdam, Meibergdreef 9, 1105AZ Amsterdam, The Netherlands (E-mail: r.delewi@ amsterdamumc.nl).

2666-2736

Copyright $(2021$ The Author(s). Published by Elsevier Inc. on behalf of The American Association for Thoracic Surgery. This is an open access article under the CC BY license (http://creativecommons.org/licenses/by/4.0/).

https://doi.org/10.1016/j.xjon.2021.03.012 


\section{Abbreviations and Acronyms \\ $\mathrm{BE}=$ balloon expandable \\ BMI = body mass index \\ CENTER $=$ Cerebrovascular Events in Patients \\ Undergoing Transcatheter Aortic Valve Implantation \\ $\mathrm{SE} \quad=$ self-expandable \\ TAVI $=$ transcatheter aortic valve implantation \\ VARC 2 = Second Valve Academic Research Consortium}

Video clip is available online.

Transcatheter aortic valve implantation (TAVI) is a treatment option for patients with severe symptomatic aortic valve stenosis. Its indication has expanded from inoperable to low risk patients. ${ }^{1-6}$

Obesity is an epidemic associated with the metabolic syndrome, including diabetes mellitus, dyslipidemia, obstructive sleep apnea, and increased risk of developing cardiovascular diseases. ${ }^{7}$ Obesity reduces life expectancy in general and increases the challenge of surgical procedures, with longer operation times and postoperative complications, such as wound infections. ${ }^{8,9}$ Paradoxically, overweight and obesity have sometimes been associated with improved survival in patients with cardiovascular conditions, particularly after surgical procedures such as surgical aortic valve replacement and coronary artery bypass grafting. ${ }^{10-15}$ On the other hand, in elderly patients, low weight is frequently associated with frailty and cardiac cachexia, leading to worse outcomes after invasive procedures. ${ }^{16,17}$ Data on influence of body mass index (BMI) on complication rates and outcomes after TAVI are scarce.

In this study, we merged patient-level data from several global registries and prospective studies for $>12,000$ patients undergoing transfemoral TAVI. ${ }^{18}$ The aim of this analysis was to assess the effect of BMI on the outcomes after TAVI.

\section{METHODS}

\section{Study Design and Patient Sample}

The Cerebrovascular Events in Patients Undergoing Transcatheter Aortic Valve Implantation (CENTER) study is an international collaboration, including patients with severe aortic valve stenosis undergoing transfemoral TAVI with balloon-expandable devices (BE) (Edwards lifesciences Inc, Irvine Calif) or self-expandable devices (SE) (Medtronic Inc, Minneapolis, Minn). The study is registered at CinicalTrials.gov (NCT03588247). A more detailed description on study design, eligibility criteria, systematic search methodology, and data collection has been reported elsewhere. ${ }^{19}$ Briefly, the CENTER collaboration includes data from 3 national registries, 2 multicenter prospective registries, 4 singlecenter prospective registries, and 1 randomized clinical trial identified through a systematic online search on PubMed. Therefore, the collaboration comprises a global patient sample with patients treated in the United States of America, Brazil, Israel, and Europe. All studies were conducted according to the Declaration of Helsinki and all patients provided written informed consent at each participating center. Collaborators provided a dedicated database with baseline patient characteristics, echocardiography data, procedural information, and long-term clinical follow-up data. In total, 12,381 patients undergoing transfemoral TAVI between 2007 and 2018 with BE or SE valves were included in the CENTER study. BMI was calculated as weight in kilograms divided by the square of height in meters. Categorization of the BMI was adopted from the World Health Organization and National Institutes of Health and defined as underweight $(<18.5$ $\mathrm{kg} / \mathrm{m}^{2}$ ), normal weight $\left(18.5-24.9 \mathrm{~kg} / \mathrm{m}^{2}\right)$, overweight $\left(25.0-29.9 \mathrm{~kg} / \mathrm{m}^{2}\right)$, and obese $\left(\geq 30.0 \mathrm{~kg} / \mathrm{m}^{2}\right)$. For a more detailed analysis of outcomes in the obesity category, it was subsequently subdivided in obese (30.0-34.9 $\left.\mathrm{kg} / \mathrm{m}^{2}\right)$, very obese $\left(35.0-39.9 \mathrm{~kg} / \mathrm{m}^{2}\right)$, and severely obese $\left(\geq 40.0 \mathrm{~kg} / \mathrm{m}^{2}\right)$.

\section{Study Endpoints}

The primary endpoints of this analysis were differences in 30-day and 1year all-cause mortality after TAVI between BMI categories (underweight: $<18.5$, normal weight: $18.5-24.9$, overweight: $25.0-29.9$, and obese: $\geq 30.0$ $\mathrm{kg} / \mathrm{m}^{2}$ ). Secondary outcomes included incidence of in-hospital mortality, stroke, myocardial infarction, life-threatening or major bleeding, requirement for permanent pacemaker and new-onset atrial fibrillation, as well as 30-day and 1-year stroke rates. All outcomes were reported as defined by the standardized definitions from the Second Valve Academic Research Consortium (VARC2) ${ }^{20}$ Outcomes were adjudicated by the adjudication committee in 6 of the 10 participating centers. ${ }^{18}$

\section{Statistical Analysis}

We applied multiple imputation methods to estimate missing data in baseline medical history. The imputation procedure and multivariate regression models were performed according to the Rubin's protocol under the assumption that missing data are missing at random. Baseline values of continuous variables were tested for normal distribution and reported as mean \pm standard deviation or median with interquartile range (IQR, 25th-75th percentile) as appropriate. Afterwards, the 1-way analysis of variance for continuous covariates or Kruskal-Wallis test was used to determine differences between BMI categories. Baseline categorical variables were presented as frequencies and percentages, differences between groups were tested with the Pearson $\chi^{2}$ test. The difference in incidence of inhospital and 30-day outcomes for underweight, normal weight, overweight, and obese patients were reported. The normal weight group was used as reference group and we estimated odds ratios (ORs) and $95 \%$ confidence intervals (CIs) for 30-day mortality in the other BMI categories using logistic regression. Furthermore, baseline patient characteristics were explored as predictors of 30-day mortality, using logistic regression methods. Each potential predictor, dichotomous or continuous, was tested in a univariate model: those variables known from the literature or with $P<.10$ were combined in a multivariate model and presented as OR and 95\% CI. Cox proportional hazards regression curves were made to assess cumulative 1-year mortality of the BMI groups and hazard ratios (HR) were reported. We included a frailty term to adjust for possible confounding. A frailty term $(\gamma)$ assessed random effects and heterogeneity between trials and because of unmeasured factors. We corrected for possible clustering with generalized least squares model because data were collected from different centers that could influence outcomes. Sensitivity analyses were performed using $E$ values, which indicate robustness of an association to potential confounding. ${ }^{21}$ All statistical tests were 2 -tailed. Because 10 secondary 
outcomes were tested, Bonferroni adjustment for multiple testing was applied. All calculations were generated by SPSS software version 26.0 for Windows (IBM-SPSS, Inc, Armonk, NY).

\section{RESULTS \\ Patient Population}

A total of 12,381 patients were included. Median age was 83 years (IQR, 80-88 years), 58\% were women, and mean BMI was $27.2 \pm 4.9 \mathrm{~kg} / \mathrm{m}^{2}$. Two percent of patients $(n=205)$ were underweight, $29 \%(n=3553)$ were normal weight, $44 \%(\mathrm{n}=5470)$ were overweight, and $25 \%$ ( $n=3150)$ were obese. Baseline characteristics of patients according to BMI category are presented in Table 1. Cardiovascular risk factors such as hypertension, diabetes mellitus and dyslipidemia increased progressively with increase of BMI category. Low glomerular filtration rate $<30 \mathrm{~mL} /$ $\mathrm{min} / 1.73 \mathrm{~m}^{2}$ was inversely correlated with BMI category: from $29 \%$ in underweight to $8 \%$ in obese patients $(P<.001)$. Mortality risk prediction scores, Logistic European System for Cardiac Operative Risk Evaluation, European System for Cardiac Operative Risk Evaluation II, and Society of Thoracic Surgeons Predicted Risk of Mortality were lower with increase in BMI category.

\section{Mortality}

Mean follow-up was $464 \pm 536$ days and median followup was 365 days (IQR, 56-667 days). In-hospital outcomes were $98 \%$ complete and 30-day outcomes were complete in $91 \%$ of patients. Missing data per BMI category are displayed in Table E1. In-hospital and 30-day outcomes according to BMI categories are summarized in Table 2 and Figure 1. Thirty-day mortality was $6.9 \%$ in normal weight patients (reference category). Thirty-day mortality was highest in underweight patients $(9.8 \%$, OR, 1.51; 95\% CI, $0.92-2.47 ; P=.010)$. Mortality was $5.3 \%$ in overweight and $5.2 \%$ in obese patients (OR, $0.73 ; 95 \% \mathrm{CI}, 0.61-0.88$; $P=.001$ and OR, 0.74; 95\% CI, 0.60-0.92; $P=.006$, respectively).

Obese patients were further subdivided into obese (BMI 30.0-34.9), very obese (BMI 35.0-39.9), and severely obese patients (BMI $\geq 40.0$ ). Thirty-day mortality was $4.8 \%$ in obese, $6.6 \%$ in very obese, and $7.5 \%$ in severely obese patients (Figure 2). Very and severely obese patients did not show a survival benefit compared with normal weight patients (OR, 0.95; 95\% CI, 0.67-1.35; $P=.79$ and OR, $1.09 ; 95 \%$ CI, 0.62-1.84; $P=.76$, respectively).

To further gain insight into the association of BMI and 30-day mortality, we presented HRs of BMI using the median BMI of 27.0 as reference value in Figure 3. There was no difference in 30-day mortality for BMI categories between different centers where TAVI was performed $(z=0.71 ; P=.48)$. Thirty-day mortality did not differ between BE valves compared with $\mathrm{SE}$ valves in each BMI category (Table E2). In a multivariate analysis, BMI categories were not independent predictors of 30-day mortality (Table 3).

One-year mortality was lowest in overweight $(15.5 \%$, HR, $0.80 ; 95 \%$ CI, 0.71-0.91; $P<.001)$ and obese patients (15.7\%, HR, 0.81; 95\% CI, 0.71-0.94; $P=.005)$, and highest in underweight patients $(28.7 \%, \mathrm{HR}, 1.56$; $95 \% \mathrm{CI}$; $1.15-2.18 ; P=.005)$ compared with normal weight (18.9\%, reference) (Tables 2 and 4 ). In a multivariate cox regression model, 1-year mortality remained significantly higher in underweight (HR, 1.52; 95\% CI, 1.10-2.09; $P=.011$ ), but in not overweight and obese patients (Table 4). Kaplan-Meier survival curves per BMI category are displayed in Figure 4.

\section{Other Clinical Outcomes}

In hospital and 30-day stroke rates were similar across BMI groups (Table 2). Thirty-day stroke rates were comparable between centers with and without an adjudication committee. ${ }^{18}$ Also, 1-year stroke rates were not significantly different between BMI categories (Tables 3 and 4).

Similarly, no differences were observed for myocardial infarction and new onset atrial fibrillation (Tables 2 and 3). Major or life-threatening bleeding was less frequent in obese patients $(4.4 \%$ in obese vs $5.9 \%$ in underweight, $6.3 \%$ in normal weight, and $6.0 \%$ in overweight patients; $P=.001)$. Even after multivariate adjustment, bleeding incidence was lower in overweight (OR, 0.74; 95\% CI, $0.59-0.94 ; P=.012$ ) and obese patients (OR, 0.62; 95\% CI, $0.46-0.82 ; P=.001)$. On the contrary, pacemaker implantation occurred more frequently in overweight (15.0\%, OR, 1.26; 95\% CI, 1.10-1.44; $P=.001)$ and obese patients $(14.8 \%$, OR, $1.27 ; 95 \% \mathrm{CI}, 1.10-1.48 ; P=.001)$, as opposed to normal weight and underweight patients $(12.3 \%$ and $9.8 \%$, respectively, $P=.001)$. Pacemaker implantation rates remained higher after multivariate adjustment in overweight (OR, 1.30; 95\% CI, 1.10-1.53; $P=.002)$ and obese patients (OR, 1.30; 95\% CI, 1.07$1.58 ; P=.001)$. Device success, as defined by VARC $2,{ }^{20}$ was lower in underweight patients: $89.9 \%$ compared with $94.1 \%$ in normal weight, $95.1 \%$ in overweight, and $95.7 \%$ in obesity $(P=.001)$. Hospital stay was longer in underweight patients: 8 days (IQR, 6-12 days) versus 7 days (IQR, 5-11 days) in the other BMI groups $(P<.001)$.

\section{DISCUSSION \\ Main Results}

In this large global cohort we found that overweight and obese patients showed lower 30-day mortality compared with normal weight patients. However in multivariate analysis, there were no differences in 30-day mortality across BMI groups. Nonetheless at 1-year follow-up, underweight patients showed higher 1-year mortality rates. Stroke rates did not differ across BMI categories. Obese and overweight patients less frequently experienced major or life- 
TABLE 1. Baseline patient characteristics of patients undergoing transcatheter aortic valve implantation according to body mass index category

\begin{tabular}{|c|c|c|c|c|c|c|}
\hline & \multicolumn{5}{|c|}{ BMI category } & \multirow[b]{2}{*}{$P$ value } \\
\hline & $\begin{array}{c}\text { Total } \\
(\mathrm{N}=12,381)\end{array}$ & $\begin{array}{c}<18.5 \mathrm{~kg} / \mathrm{m}^{2} \\
(\mathrm{n}=\mathbf{2 0 5})\end{array}$ & $\begin{array}{c}18.5-24.9 \mathrm{~kg} / \mathrm{m}^{2} \\
(\mathrm{n}=3564)\end{array}$ & $\begin{array}{c}25-29.9 \mathrm{~kg} / \mathrm{m}^{2} \\
(\mathrm{n}=5460)\end{array}$ & $\begin{array}{l}\geq 30 \mathrm{~kg} / \mathrm{m}^{2} \\
(\mathrm{n}=3152)\end{array}$ & \\
\hline \multicolumn{7}{|l|}{ Demographics } \\
\hline Age (y) & $83(78-86)$ & $84(80-88)$ & $84(80-87)$ & $83(79-86)$ & $81(77-85)$ & $<.001$ \\
\hline Female sex & $7105(58)$ & $170(83)$ & $2147(60)$ & $2823(52)$ & $1965(63)$ & $<.001$ \\
\hline \multicolumn{7}{|l|}{ Medical history } \\
\hline Stroke or TIA & $1288(10)$ & $23(11)$ & $354(10)$ & $598(11)$ & $313(10)$ & .35 \\
\hline Myocardial infarction & $1666(14)$ & $24(12)$ & $456(13)$ & $786(14)$ & $400(13)$ & .07 \\
\hline Previous PCI & $2654(22)$ & $26(13)$ & $743(21)$ & $1205(22)$ & $680(22)$ & .01 \\
\hline Previous CABG & $1469(12)$ & $7(3)$ & $395(11)$ & 699 (13) & $368(12)$ & $<.001$ \\
\hline Hypertension & 9714 (79) & $134(65)$ & $2540(72)$ & $4356(80)$ & $2684(86)$ & $<.001$ \\
\hline Diabetes mellitus & $3867(31)$ & $32(16)$ & $808(23)$ & $1664(31)$ & $1363(43)$ & $<.001$ \\
\hline Dyslipidemia & $6778(55)$ & $83(41)$ & $1697(48)$ & $3064(56)$ & $1934(62)$ & $<.001$ \\
\hline Peripheral vascular disease & $1814(15)$ & $31(15)$ & $553(16)$ & 846 (16) & 373 (12) & $<.001$ \\
\hline Coronary artery disease & $5070(41)$ & $75(37)$ & $1506(42)$ & $2298(42)$ & $1191(38)$ & $<.001$ \\
\hline Atrial fibrillation & $3345(27)$ & $50(24)$ & $959(27)$ & $1493(27)$ & $843(27)$ & .79 \\
\hline $\mathrm{GFR}<30 \mathrm{~mL} / \mathrm{min} / 1.73 \mathrm{~m}^{2}$ & $1682(14)$ & $59(29)$ & $691(20)$ & $674(12)$ & $256(8)$ & $<.001$ \\
\hline \multicolumn{7}{|l|}{ Risk scores } \\
\hline Logistic EuroSCORE (\%) & $15.0(9.5-23.0)$ & $17.4(11.8-29.1)$ & $16.0(10.1-25.6)$ & $15.0(9.5-22.6)$ & $13.2(8.8-20.7)$ & $<.001$ \\
\hline EuroSCORE II $(\%)$ & $4.0(2.3-6.9)$ & $4.8(3.3-7.9)$ & $4.1(2.6-7.1)$ & $3.9(2.3-6.9)$ & $3.7(2.1-6.0)$ & $<.001$ \\
\hline STS-PROM (\%) & $6.4(4.0-13.0)$ & $9.6(5.2-18.3)$ & $7.5(4.6-14.5)$ & $6.0(3.8-12.2)$ & $5.8(3.4-11.2)$ & $<.001$ \\
\hline \multicolumn{7}{|c|}{ Echocardiographic aortic characteristics } \\
\hline Max gradient $(\mathrm{mm} \mathrm{Hg})$ & $79 \pm 23$ & $84 \pm 26$ & $80 \pm 24$ & $79 \pm 23$ & $79 \pm 23$ & .02 \\
\hline Mean gradient $(\mathrm{mm} \mathrm{Hg})$ & $51 \pm 17$ & $53 \pm 20$ & $51 \pm 18$ & $51 \pm 18$ & $50 \pm 16$ & .002 \\
\hline Aortic valve area $\left(\mathrm{cm}^{2}\right)$ & $0.7 \pm 0.2$ & $0.6 \pm 0.2$ & $0.6 \pm 0.2$ & $0.7 \pm 0.2$ & $0.7 \pm 0.2$ & $<.001$ \\
\hline \multicolumn{7}{|l|}{ Device type } \\
\hline Balloon-expandable valve & $6226(50)$ & $96(47)$ & $1844(52)$ & $2785(51)$ & $1501(48)$ & .004 \\
\hline Self-expandable valve & $6131(50)$ & $109(53)$ & $1708(48)$ & $2675(49)$ & $1639(52)$ & .004 \\
\hline
\end{tabular}

Values are presented as median (interquartile range), $\mathrm{n}(\%)$, or mean \pm standard deviation. BMI, Body mass index; TIA, transient ischemic attack; $P C I$, percutaneous coronary intervention; $C A B G$, coronary artery bypass grafting; GFR, glomerular filtration rate; EuroSCORE, European System for Cardiac Operative Risk Evaluation; STS-PROM, Society of Thoracic Surgeons Predicted Risk of Mortality.

TABLE 2. Unadjusted in-hospital, 30-day, and 1-year clinical outcomes according to body mass index category

\begin{tabular}{|c|c|c|c|c|}
\hline \multirow[b]{2}{*}{ Outcome } & \multicolumn{4}{|c|}{ BMI category } \\
\hline & $<18.5 \mathrm{~kg} / \mathrm{m}^{2}(\mathrm{n}=205)$ & $18.5-24.9 \mathrm{~kg} / \mathrm{m}^{2}(\mathrm{n}=3564)$ & $25-29.9 \mathrm{~kg} / \mathrm{m}^{2}(\mathrm{n}=5460)$ & $>30.0 \mathrm{~kg} / \mathrm{m}^{2}(\mathrm{n}=3152)$ \\
\hline \multicolumn{5}{|l|}{ During hospital admission } \\
\hline Mortality & $14(8.4)$ & $184(6.2)$ & $205(4.3)$ & $134(4.6)$ \\
\hline Stroke & $4(2.1)$ & $79(2.4)$ & $96(1.9)$ & $51(1.7)$ \\
\hline Myocardial infarction & $0(0.0)$ & $27(0.8)$ & $37(0.7)$ & $20(0.7)$ \\
\hline Major or life-threatening bleeding & $10(5.9)$ & $191(6.3)$ & $284(6.0)$ & $123(4.4)$ \\
\hline New onset atrial fibrillation & $8(6.1)$ & $110(6.0)$ & $105(4.7)$ & $57(5.8)$ \\
\hline Permanent pacemaker implantation & $18(9.8)$ & $338(12.3)$ & $697(15.0)$ & $421(14.8)$ \\
\hline \multicolumn{5}{|l|}{ At $30 \mathrm{~d}$} \\
\hline Mortality & $18(9.8)$ & $218(6.9)$ & $254(5.3)$ & $144(5.2)$ \\
\hline Stroke & $4(2.2)$ & $88(2.8)$ & $112(2.3)$ & $56(2.0)$ \\
\hline \multicolumn{5}{|l|}{ At $1 \mathrm{y}$} \\
\hline Mortality & $41(28.7)$ & $458(18.9)$ & $538(15.5)$ & $325(15.7)$ \\
\hline Stroke & $10(6.9)$ & $137(5.6)$ & $186(5.3)$ & $90(4.3)$ \\
\hline
\end{tabular}

Values are presented as n (\%). Data about in-hospital mortality was complete in $98 \%$; in-hospital stroke in $98 \%$; myocardial infarction in $94 \%$; major bleeding in $91 \%$; newonset atrial fibrillation in $57 \%$; pacemaker implantation in $92 \%$; 30-day mortality in $91 \%$; 30-day stroke in $91 \%$; 1 -year mortality in $66 \%$; and 1 -year stroke in $66 \%$. BMI, Body mass index. 


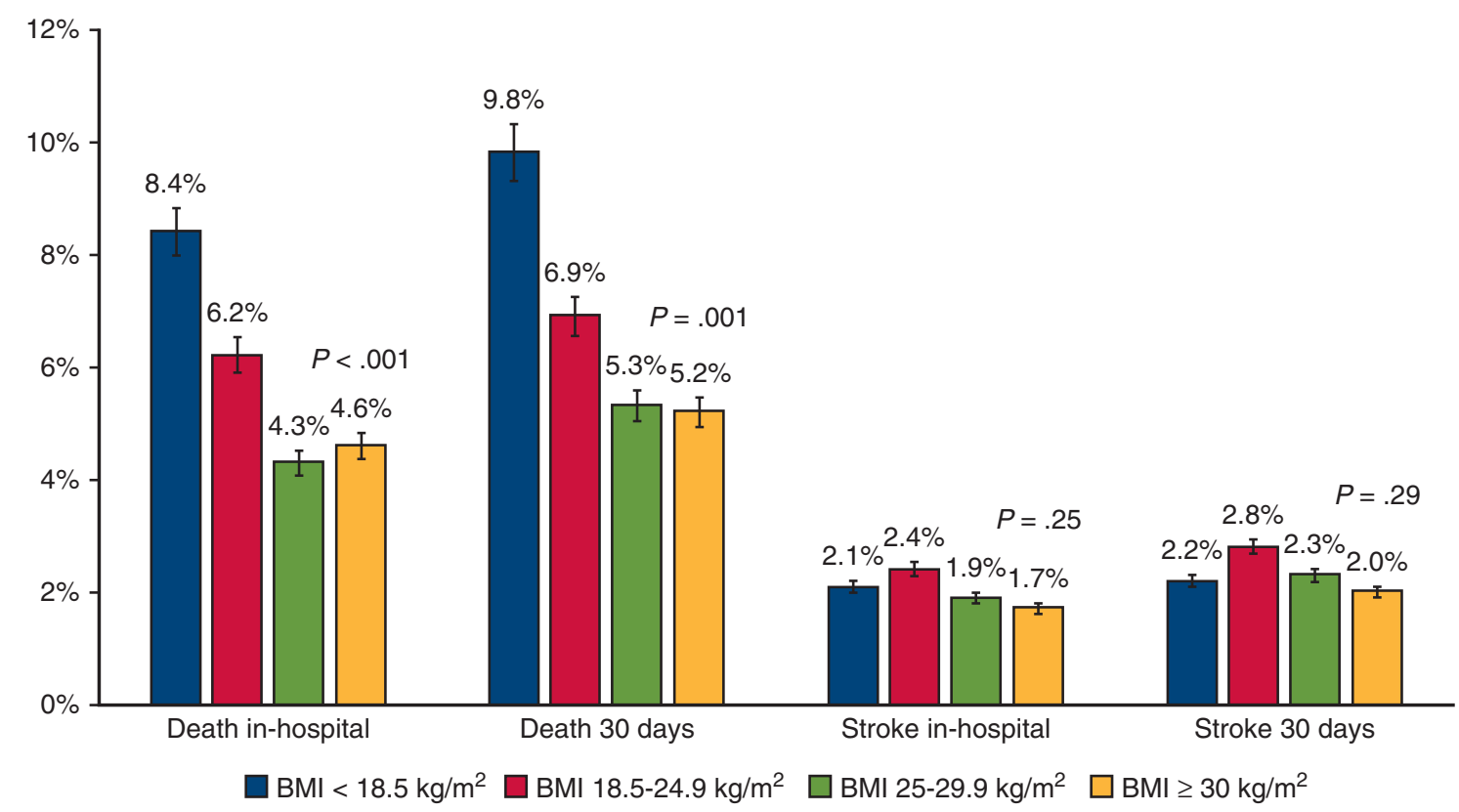

FIGURE 1. Incidence of 30-day and in-hospital all-cause mortality and stroke according to body mass index (BMI) categories: blue indicates underweight, red indicates normal weight, green indicates overweight, and yellow indicates obesity.

threatening bleeding, but more frequently had a permanent pacemaker implanted. Figure 5 summarizes our findings. The main results are discussed by the fist author in Video 1 .

\section{Obesity in TAVI Patients}

In the present study, overweight and obese TAVI patients seem to have a prognosis benefit in univariate analysis. Previous studies showed a linear relationship between each 1 unit of BMI increase and survival. ${ }^{22}$ A subanalysis of the French Aortic National CoreValve and Edwards 2 Registry described better midterm survival for obese patients. ${ }^{23}$

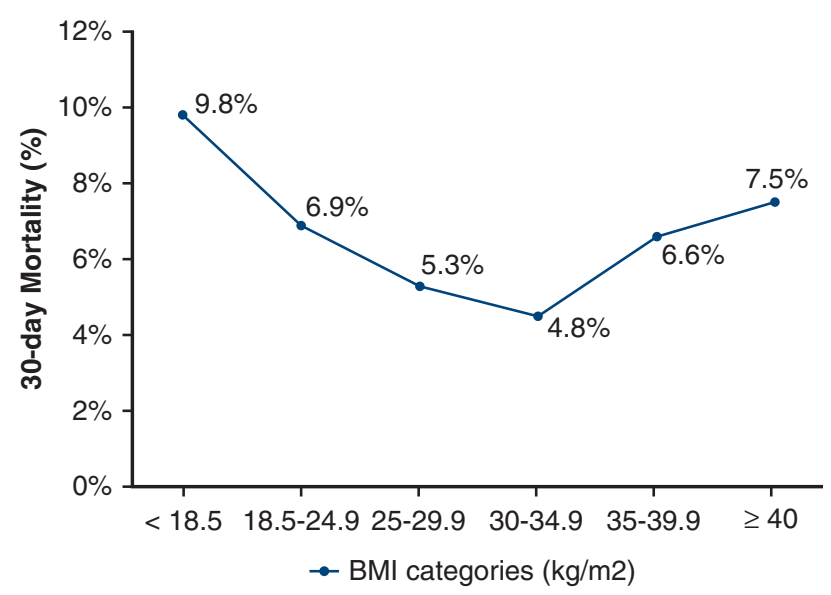

FIGURE 2. Thirty-day all-cause mortality according to body mass index (BMI) categories: $<18.5$ is underweight, 18.5 to 24.9 is normal weight, 25.0 to 29.9 is overweight, 30.0 to 34.9 is obese, 35.0 to 39.9 is very obese, and $\geq 40$ is severely obese.
Numbers of patients with extreme obesity were low but they describe a possible trend toward increased mortality for severely obese patients. In univariate analysis, we found an inverted $J$-shaped relationship in our cohort, with highest mortality rates for underweight and severely obese patients. This is consistent with Gonzalez Ferreiro and colleagues, ${ }^{24}$ suggesting a $J$-shaped relationship of mortality with BMI. In our cohort, the association of BMI and mortality was not significant after multivariate adjustment, which is consistent with studies of patients undergoing surgical aortic valve replacement. ${ }^{15}$ Despite not being an

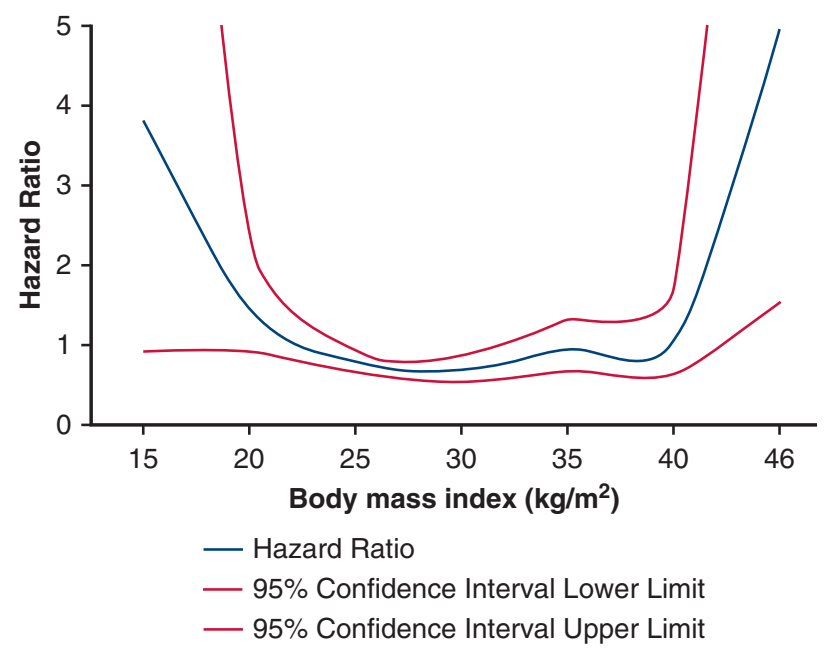

FIGURE 3. Association between body mass index (BMI) and hazard ratios for 30-day mortality compared with median BMI as a reference value. Red lines present upper and lower limits of the $95 \%$ confidence interval. 
TABLE 3. In-hospital and 30-day outcomes according to body mass index category

\begin{tabular}{|c|c|c|c|c|c|c|}
\hline Category & $\begin{array}{c}\text { Unadjusted odds } \\
\text { ratio }(95 \% \text { confidence } \\
\text { interval }) \\
\end{array}$ & $P$ value & $E$ value & $\begin{array}{c}\text { Adjusted odds } \\
\text { ratio }(95 \% \text { confidence } \\
\text { interval }) \\
\end{array}$ & $P$ value & $E$ value \\
\hline \multicolumn{7}{|c|}{ In hospital mortality } \\
\hline Underweight & $1.49(0.87-2.53)$ & .14 & 2.43 & $1.03(0.54-1.97)$ & .92 & 1.21 \\
\hline Normal weight & Reference & - & & Reference & - & \\
\hline Overweight & $0.76(0.63-0.93)$ & .007 & 1.96 & $0.83(0.64-1.07)$ & .15 & 1.70 \\
\hline Obese & $0.80(0.64-1.00)$ & .048 & 1.81 & $0.94(0.70-1.28)$ & .70 & 1.32 \\
\hline \multicolumn{7}{|l|}{ In hospital stroke } \\
\hline Underweight & $0.82(0.30-2.52)$ & .70 & 1.74 & $0.66(0.20-2.14)$ & .49 & 2.40 \\
\hline Normal weight & Reference & - & & Reference & - & \\
\hline Overweight & $0.82(0.61-1.10)$ & .18 & 1.74 & $0.88(0.62-1.25)$ & .47 & 1.53 \\
\hline Obese & $0.76(0.54-1.08)$ & .12 & 1.96 & $0.68(0.43-1.08)$ & .11 & 2.30 \\
\hline \multicolumn{7}{|c|}{ Myocardial infarction } \\
\hline Underweight & 0.00 & 1.00 & - & 0.00 & 1.00 & - \\
\hline Normal weight & Reference & - & & Reference & - & \\
\hline Overweight & $0.90(0.55-1.47)$ & .68 & 1.46 & $0.94(0.49-1.79)$ & .84 & 1.32 \\
\hline Obese & $0.84(0.48-1.48)$ & .55 & 1.67 & $1.11(0.54-2.27)$ & .78 & 1.46 \\
\hline \multicolumn{7}{|c|}{ Major- or life-threatening bleeding } \\
\hline Underweight & $0.92(0.51-1.68)$ & .79 & 1.39 & $0.92(0.49-1.75)$ & .81 & 1.39 \\
\hline Normal weight & Reference & - & & Reference & - & \\
\hline Overweight & $0.91(0.76-1.09)$ & .32 & 1.43 & $0.74(0.59-0.94)$ & .012 & 1.32 \\
\hline Obese & $0.65(0.52-0.81)$ & $<.001$ & 2.45 & $0.62(0.46-0.82)$ & .001 & 2.61 \\
\hline \multicolumn{7}{|c|}{ New-onset atrial fibrillation } \\
\hline Underweight & $1.11(0.52-2.35)$ & .79 & 1.46 & $1.36(0.63-2.93)$ & .44 & 2.06 \\
\hline Normal weight & Reference & - & & Reference & - & \\
\hline Overweight & $0.88(0.65-1.17)$ & .36 & 1.53 & $0.92(0.66-1.29)$ & .64 & 1.39 \\
\hline Obese & $1.11(0.79-1.57)$ & .56 & 1.46 & $1.26(0.85-1.88)$ & .26 & 1.83 \\
\hline \multicolumn{7}{|c|}{ Permanent pacemaker implantation } \\
\hline Underweight & $0.77(0.48-1.25)$ & .29 & 1.92 & $0.68(0.37-1.25)$ & .21 & 2.30 \\
\hline Normal weight & Reference & - & & Reference & - & \\
\hline Overweight & $1.26(1.10-1.44)$ & .001 & 1.83 & $1.30(1.10-1.53)$ & .002 & 1.92 \\
\hline Obese & $1.27(1.10-1.48)$ & .001 & 1.86 & $1.30(1.07-1.58)$ & .009 & 1.92 \\
\hline \multicolumn{7}{|l|}{ 30-d mortality } \\
\hline Underweight & $1.51(0.92-2.47)$ & .10 & 2.39 & $1.14(0.63-2.04)$ & 67 & 1.54 \\
\hline Normal weight & Reference & - & & Reference & - & \\
\hline Overweight & $0.73(0.61-0.88)$ & .001 & 2.08 & $0.80(0.63-1.01)$ & .06 & 1.81 \\
\hline Obese & $0.74(0.60-0.92)$ & .006 & 2.04 & $0.92(0.68-1.21)$ & .52 & 1.39 \\
\hline \multicolumn{7}{|l|}{ 30-d stroke } \\
\hline Underweight & $0.91(0.37-2.26)$ & .84 & 1.39 & $0.82(0.30-2.30)$ & .71 & 1.74 \\
\hline Normal weight & Reference & - & & Reference & - & \\
\hline Overweight & $0.86(0.66-1.13)$ & .27 & 1.60 & $0.92(0.66-1.27)$ & .60 & 1.39 \\
\hline Obese & $0.74(0.53-1.02)$ & .06 & 2.04 & $0.68(0.44-1.05)$ & .08 & 2.30 \\
\hline
\end{tabular}

The multivariate model included age, sex, history of percutaneous coronary intervention, history of coronary artery bypass graft, diabetes mellitus, hypertension, dyslipidemia, glomerular filtration rate $<30 \mathrm{~mL} / \mathrm{min} / 1.73 \mathrm{~m}^{2}$, valve type, mean aortic valve gradient, and logistic European System for Cardiac Operative Risk Evaluation and Society of Thoracic Surgeons Predicted Risk of Mortality.

independent predictor for 30-day mortality, we studied how the outcomes are in obese patients undergoing TAVI. In clinical practice, obese patients come with their comorbidities and often metabolic syndrome, not just increased body weight. Therefore, the unadjusted results have clinical value because they represent outcomes of the total picture of obese patients undergoing TAVI.
A possible simple factor contributing to improved survival in overweight and obese patients is that these patients were younger when undergoing TAVI. Obesity can be a contraindication for cardiac surgery in the heart team decision making process. It could also be postulated that patients with obesity show symptoms of severe aortic stenosis at an earlier stage, such as dyspnea, due to the aggravating 
TABLE 4. One-year outcomes according to body mass index category

\begin{tabular}{|c|c|c|c|c|c|c|}
\hline Category & $\begin{array}{c}\text { Unadjusted hazard } \\
\text { ratio }(95 \% \text { confidence } \\
\text { interval }) \\
\end{array}$ & $P$ value & $E$ value & $\begin{array}{c}\text { Adjusted hazard } \\
\text { ratio }(95 \% \text { confidence } \\
\text { interval }) \\
\end{array}$ & $P$ value & $E$ value \\
\hline \multicolumn{7}{|l|}{ 1-y mortality } \\
\hline Underweight $(\mathrm{n}=205)$ & $1.56(1.15-2.18)$ & .005 & 2.06 & $1.52(1.10-2.09)$ & .011 & 2.01 \\
\hline Normal weight $(\mathrm{n}=3564)$ & Reference & - & & Reference & - & \\
\hline Overweight $(\mathrm{n}=5460)$ & $0.80(0.71-0.91)$ & $<.001$ & 1.61 & $0.89(0.79-1.02)$ & .09 & 1.39 \\
\hline Obese $(\mathrm{n}=3152)$ & $0.81(0.71-0.94)$ & .005 & 1.58 & $0.95(0.82-1.10)$ & .96 & 1.23 \\
\hline \multicolumn{7}{|l|}{1 -y stroke } \\
\hline Underweight & $1.00(0.41-1.45)$ & .99 & 1.00 & $1.00(0.40-2.49)$ & 1.00 & 1.00 \\
\hline Normal weight & Reference & - & & Reference & - & \\
\hline Overweight & $0.89(0.67-1.18)$ & .43 & 1.50 & $0.94(0.68-1.30)$ & .71 & 1.32 \\
\hline Obese & $0.76(0.54-1.06)$ & .76 & 1.96 & $0.74(0.49-1.13)$ & .17 & 2.04 \\
\hline
\end{tabular}

The multivariate model included age, sex, history of percutaneous coronary intervention, history of coronary artery bypass graft, diabetes mellitus, hypertension, dyslipidemia, glomerular filtration rate $<30 \mathrm{~mL} / \mathrm{min} / 1.73 \mathrm{~m}^{2}$, valve type, mean aortic valve gradient, logistic European System for Cardiac Operative Risk Evaluation, and Society of Thoracic Surgeons Predicted Risk of Mortality.

factor of excess body weight. Furthermore, they had significantly lower rates of severe kidney disease, a comorbidity strongly associated with mortality. ${ }^{25}$ Obese patients present a greater metabolic and physical reserve, potentiating a better tolerance for weight loss in stressful situations, such as undergoing a hospitalization for TAVI, and catabolic states, such as heart failure. ${ }^{26}$ Additionally, it has been demonstrated that patients with higher BMI show better adherence to guideline recommended treatment and they probably are treated more aggressively with cardioprotective drugs, conferring a better prognosis. ${ }^{27}$ As such, in overweight and obese patients, it looks like benefits of an increased BMI outweigh the risks, leading to better survival rates. This relationship seems to invert for extremely obese patients, where the comorbidities associated to their condition mitigate the benefits of increased body weight.

\section{Low BMI: A Surrogate for Frailty}

Patients with a BMI $<18.5 \mathrm{~kg} / \mathrm{m}^{2}$ undergoing TAVI have been less well studied in previous analyses due to small sample sizes. ${ }^{17,19,20}$ In our cohort, there were 205 underweight patients, which to our knowledge corresponds to the largest number observed in this category. These patients presented a poor prognosis after TAVI, with mortality rates as high as $8.4 \%$ in-hospital, $9.8 \%$ at 30-day follow-up, and $28.7 \%$ at 1 -year follow-up. Even after multivariate adjustment, 1-year mortality was 1.5 times higher than normal weight patients. Low BMI is strongly associated with

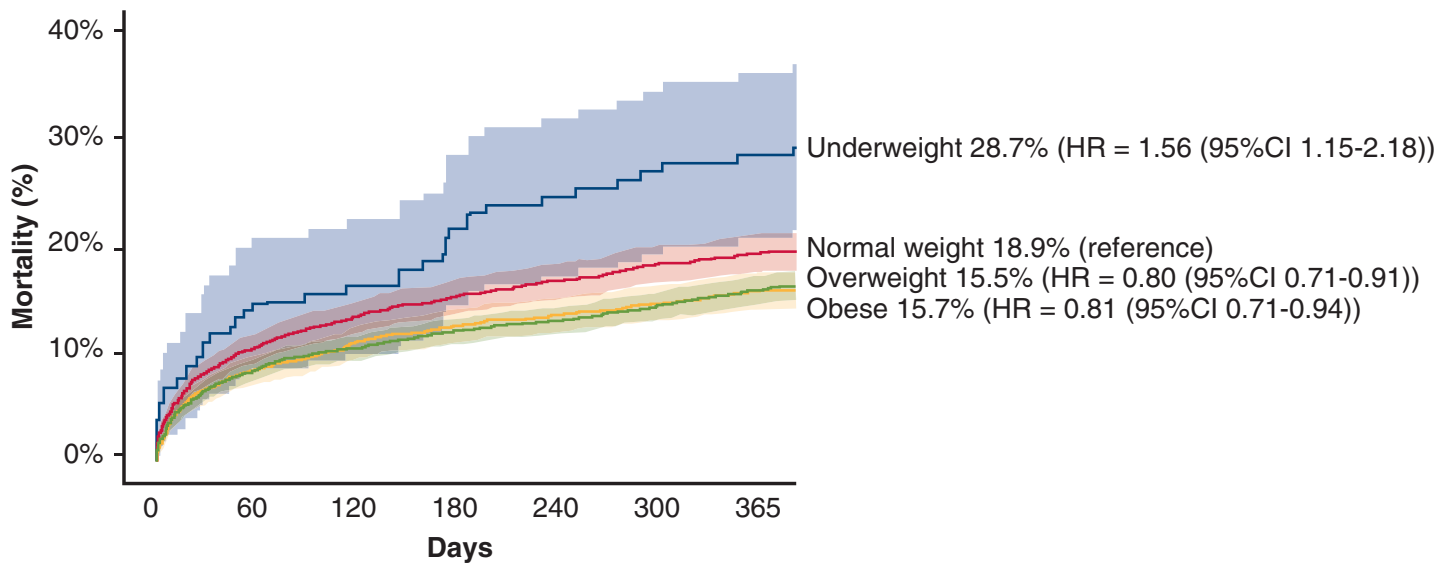

$\begin{array}{lcccc}\text { No. at risk } & & & & \\ \text { Underweight } & 183 & 130 & 102 & 83 \\ \text { Normal weight } & 3174 & 2188 & 1828 & 1659 \\ \text { Overweight } & 4845 & 3120 & 2695 & 2428 \\ \text { Obese } & 2783 & 1783 & 1555 & 1410\end{array}$

FIGURE 4. Kaplan-Meier time-to-event curves and $95 \%$ confidence intervals (CIs) for all-cause mortality according to 4 body mass index (BMI) categories up to 1 year after transcatheter aortic valve implantation. $H R$, Hazard ratio for 1-year mortality. 


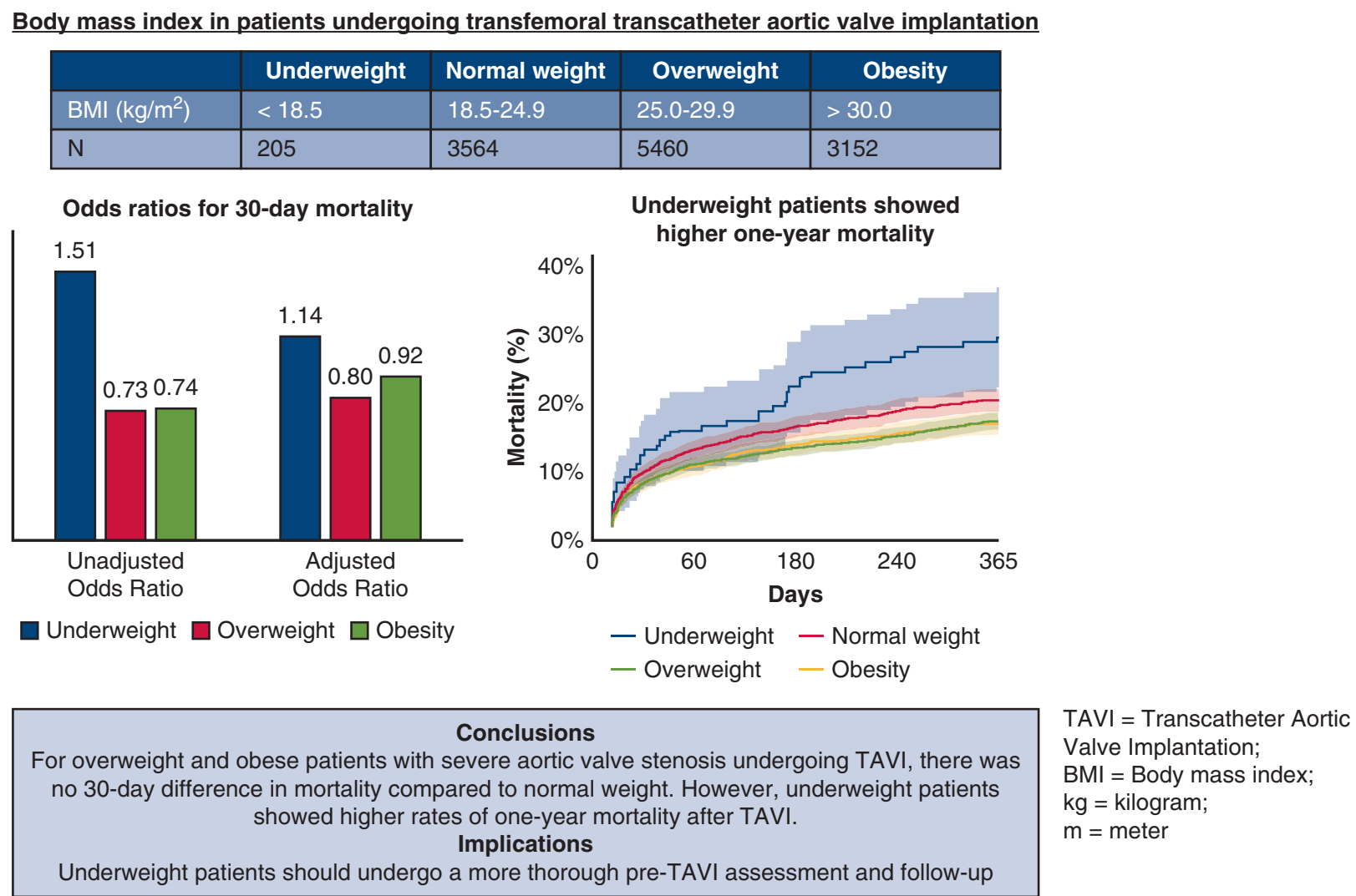

FIGURE 5. Mortality outcomes per body mass index (BMI) category in patients undergoing transcatheter aortic valve implantation (TAVI).

frailty, cardiac cachexia, and overall sicker patients. ${ }^{15,16}$ Taking these findings together, we hypothesize that a BMI $<18.5 \mathrm{~kg} / \mathrm{m}^{2}$ might be used in TAVI patients as a simple frailty discriminator. The possible lack of benefit of this invasive procedure for these very frail patients should be carefully analyzed. The difference in mortality in

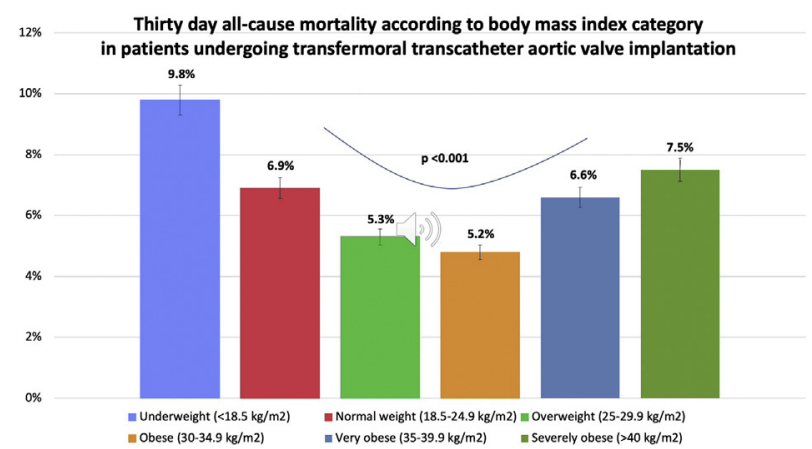

VIDEO 1. The first author briefly discusses the main results of this study. Thirty-day mortality after transcatheter aortic valve implantation was lowest in overweight and obese patients. However, after multivariate adjustment, 30-day mortality was not different across body mass index groups. Nevertheless, underweight patients showed higher 1-year mortality. Video available at: https://www.jtcvs.org/article/S2666-2736(21) 00069-3/fulltext. underweight patients was statistically significant at 1-year follow-up, but not at 30 days. This difference points toward the fact that higher 1-year mortality can be explained by deaths from other causes. These 1-year deaths may not be related to the TAVI procedure itself, but rather to overall frailty. Prior to TAVI, extensive assessment, including adjustments to improve frailty is warranted. For example, patients can be assessed by a geriatrician and nutritional status can be optimized to improve clinical outcomes. Nevertheless, TAVI should be carefully considered in patients with limited life expectancy because of comorbidities or overall frailty. Low BMI can be considered a red flag, signaling patients at increased risk of poor prognosis after TAVI. Device success, according to VARC $2,{ }^{20}$ was less often achieved in underweight patients. This finding supports the hypothesis of frailty in underweight patients.

\section{Other Clinical Outcomes}

In this analysis, BMI was not associated with rates of stroke. This is in line with previous studies. ${ }^{23,24}$ In a recent article presented by the CENTER collaboration, BMI was not an independent predictor of stroke. ${ }^{18}$ Overweight and obese patients less frequently experienced major or lifethreatening bleeding, even after multivariate adjustment. This is consistent with other studies reporting higher 
bleeding incidence in underweight and lower bleeding incidence in obese patients after TAVI ${ }^{23}$ cardiac valve surgery, ${ }^{14}$ and percutaneous coronary intervention. ${ }^{17}$

\section{Limitations}

This study is a retrospective analysis, with all its inherent limitations. Nonetheless, it represents a global and realworld patient population of subjects undergoing transfemoral TAVI over the past decade. Secondly, although BMI is the widest used parameter to investigate the influence of body weight on outcomes, it does not give detailed information about body composition, such as the percentage of lean body mass and the fat distribution pattern (central vs peripheral). Thirdly, we recorded BMI at a single point in time (immediately before the TAVI procedure). We did not include data about weight gain or weight loss after TAVI.

\section{Impact on Daily Practice}

Thirty-day mortality was not different across BMI groups. However, 1-year mortality was higher in underweight patients. Therefore efficiency of TAVI treatment should be carefully considered in this subgroup. Moreover, interventions to improve frailty status before TAVI and a closer follow-up after TAVI are warranted.

\section{CONCLUSIONS}

In more than 12,000 patients undergoing transfemoral TAVI, overweight and obese patients showed lower 30day mortality as compared to patients with normal weight. However, no differences in 30-day mortality between BMI groups were found after multivariate adjustment. At 1-year follow-up, underweight was an independent predictor of higher mortality after TAVI.

\section{Conflict of Interest Statement}

Dr Regueiro is a proctor for Abbott Vascular. All other authors reported no conflicts of interest.

The Journal policy requires editors and reviewers to disclose conflicts of interest and to decline handling or reviewing manuscripts for which they may have a conflict of interest. The editors and reviewers of this article have no conflicts of interest.

The authors thank all participating investigators for their contributions to this collaboration.

CENTER collaborators include Flavio S. De Brito Jr, MD, PhD, and Flavio Tarasoutchi, MD (Heart Institute, University of São Paulo Medical School, São Paulo, Brazil); Marco Barbanti, MD (Division of Cardiology, Policlinico-Vittorio Emanuele Hospital, University of Catania, Italy); Ran Kornowski, MD, and Katia Orvin, MD (Cardiology Department, Rabin Medical Center, Petach Tikva, Israel); Azeem Latib, MD, and Matteo Pagnesi, MD (Interventional Cardiology Unit, San Raffaele Scientific Institute,
Milan, Italy); Augusto D’Onofrio, MD, PhD, and Giuseppe Tarantini, MD, PhD (Division of Cardiac Surgery, University of Padova, Italy); Flavio Ribichini, MD, $\mathrm{PhD}$, and Mattia Lunardi, MD (Division of Cardiology, Department of Medicine, University of Verona, Verona, Italy); Jan Baan, MD, PhD, Jan Tijssen, $\mathrm{PhD}$, and José P. S. Henriques, MD, PhD (Heart Center, Department of Clinical and Experimental Cardiology, Amsterdam UMC, University of Amsterdam, The Netherlands); Francisco Ten (Servicio de Cardiología, Hospital Universitario y Politécnico La Fe, Valencia, Spain); Nicolas Dumonteil, MD, and Angie Ghattas, MD (Clinique Pasteur, Toulouse, France); Paola D'Errigo, MSc (National Centre for Global Health-Istituto Superiore di Sanità, Rome, Italy); Juan Manuel Nogales (Servicio de Cardiología, Hospital Universitario de Badajoz, Badajoz, España); Thomas Modine, MD (Centre Hospitalier Universitaire, Lille, France); and George Dangas, MD, PhD (The Zena and Michael A. Wiener Cardiovascular Institute, Icahn School of Medicine at Mount Sinai, New York, NY).

\section{References}

1. Smith CR, Leon MB, Mack MJ, Miller DC, Moses JW, Svensson LG, et al. Transcatheter versus surgical aortic-valve replacement in high-risk patients. $N$ Engl J Med. 2011;364:2187-98.

2. Makkar RR, Fontana GP, Jilaihawi H, Kapadia S, Pichard AD, Douglas PS, et al. Transcatheter aortic-valve replacement for inoperable severe aortic stenosis. $N$ Engl J Med. 2012;366:1696-704.

3. Adams DH, Popma JJ, Reardon MJ, Yakubov SJ, Coselli JS, Deeb GM, et al. Transcatheter aortic-valve replacement with a self-expanding prosthesis. $N$ Engl J Med. 2014;370:1790-8.

4. Leon MB, Smith CR, Mack MJ, Makkar RR, Svensson LG, Kodali SK, et al. Transcatheter or surgical aortic-valve replacement in intermediate-risk patients. N Engl J Med. 2016;374:1609-20.

5. Popma JJ, Deeb GM, Yakubov SJ, Mumtaz M, Gada H, O'Hair D, et al. Transcatheter aortic-valve replacement with a self-expanding valve in low-risk patients. N Engl J Med. 2019;380:1706-15.

6. Mack MJ, Leon MB, Thourani VH, Makkar R, Kodali SK, Russo M, et al. Transcatheter aortic-valve replacement with a balloon-expandable valve in low-risk patients. N Engl J Med. 2019;380:1695-705.

7. Poirier P, Giles TD, Bray GA, Hong Y, Stern JS, Pi-Sunyer FX, et al. Obesity and cardiovascular disease: pathophysiology, evaluation, and effect of weight loss: an update of the 1997 American Heart Association Scientific Statement on Obesity and Heart Disease from the Obesity Committee of the Council on Nutrition, Physical Activity, and Metabolism. Circulation. 2006;113:898-918.

8. Berrington de Gonzalez A, Hartge P, Cerhan JR, Flint AJ, Hannan L, MacInnis RJ, et al. Body-mass index and mortality among 1.46 million white adults. N Engl J Med. 2010;363:2211-9.

9. Kurmann A, Vorburger SA, Candinas D, Beldi G. Operation time and body mass index are significant risk factors for surgical site infection in laparoscopic sigmoid resection: a multicenter study. Surg Endosc. 2011;25:3531-4.

10. Galal W, van Domburg RT, Feringa HH, Schouten O, Elhendy A, Bax JJ, et al. Relation of body mass index to outcome in patients with known or suspected coronary artery disease. Am J Cardiol. 2007;99:1485-90.

11. Roberts WC, Roberts CC, Vowels TJ, Ko JM, Filardo G, Hamman BL, et al. Effect of body mass index on survival in patients having aortic valve replacement for aortic stenosis with or without concomitant coronary artery bypass grafting. Am J Cardiol. 2011;108:1767-71.

12. Angeras O, Albertsson P, Karason K, Ramunddal T, Matejka G, James S, et al. Evidence for obesity paradox in patients with acute coronary syndromes: a report from the Swedish Coronary Angiography and Angioplasty Registry. Eur Heart J. 2013;34:345-53.

13. Smith RL II, Herbert MA, Dewey TM, Brinkman WT, Prince SL, Ryan WH, et al. Does body mass index affect outcomes for aortic valve replacement surgery for aortic stenosis? Ann Thorac Surg. 2012;93:742-6.

14. Thourani VH, Keeling WB, Kilgo PD, Puskas JD, Lattouf OM, Chen EP, et al. The impact of body mass index on morbidity and short- and long-term mortality in cardiac valvular surgery. J Thorac Cardiovasc Surg. 2011;142:1052-61.

15. Bruno VD, Chivasso P, Rapetto F, Guida G, Di Tommaso E, Chau HM, et al. Impact of body mass index on short- and long-term outcomes after isolated 
first-time surgical aortic valve replacement for aortic stenosis. J Cardiothorac Vasc Anesth. 2019:33:2995-3000.

16. Goel K, Gulati R, Reeder GS, Lennon RJ, Lewis BR, Behfar A, et al. Low body mass index, serum creatinine, and cause of death in patients undergoing percutaneous coronary intervention. J Am Heart Assoc. 2016;5:e003633.

17. Leistner DM, Bazara S, Münch C, Steiner J, Erbay A, Siegrist PT, et al. Association of the body mass index with outcomes in elderly patients ( $\geq 80$ years) undergoing percutaneous coronary intervention. Int J Cardiol. 2019;292:73-7.

18. Vlastra W, Jimenez-Quevedo P, Tchetche D, Chandrasekhar J, de Brito FS Jr, Barbanti M, et al. Predictors, incidence, and outcomes of patients undergoing transfemoral transcatheter aortic valve implantation complicated by stroke. Circ Cardiovasc Interv. 2019;12:e07546.

19. Vlastra W, Chandrasekhar J, Munoz-Garcia AJ, Tchetche D, de Brito FS Jr, Barbanti M, et al. Comparison of balloon-expandable vs. self-expandable valves in patients undergoing transfemoral transcatheter aortic valve implantation: from the CENTER-collaboration. Eur Heart J. 2019;40:456-65.

20. Kappetein AP, Head SJ, Genereux P, Piazza N, van Mieghem NM, Blackstone EH, et al. Updated standardized endpoint definitions for transcatheter aortic valve implantation: the Valve Academic Research Consortium-2 consensus document (VARC-2). Eur J Cardiothorac Surg. 2012;42:S45-60.

21. VanderWeele TJ, Ding P. Sensitivity analysis in observational research: introducing the E-value. Ann Intern Med. 2017;167:268-74.

22. van der Boon RM, Chieffo A, Dumonteil N, Tchetche D, Van Mieghem NM, Buchanan GL, et al. Effect of body mass index on short- and long-term out- comes after transcatheter aortic valve implantation. Am J Cardiol. 2013;111: 231-6.

23. Yamamoto M, Mouillet G, Oguri A, Gilard M, Laskar M, Eltchaninoff H, et al Effect of body mass index on 30- and 365-day complication and survival rates of transcatheter aortic valve implantation (from the French Aortic National CoreValve and Edwards 2 [FRANCE 2] registry). Am J Cardiol. 2013;112: 1932-7.

24. Gonzalez-Ferreiro R, Munoz-Garcia AJ, Lopez-Otero D, Avanzas P, Pascual I, Alonso-Briales JH, et al. Prognostic value of body mass index in transcatheter aortic valve implantation: a "J"-shaped curve. Int J Cardiol. 2017;232:342-7

25. Lüders F, Kaier K, Kaleschke G, Gebauer K, Meyborg M, Malyar NM, et al. Association of CKD with outcomes among patients undergoing transcatheter aortic valve implantation. Clin J Am Soc Nephrol. 2017;12:718-26.

26. deFilippi CR, Seliger SL. Obesity and survival with heart failure: still a paradox. JACC Heart Fail. 2017;5:64-6.

27. Lancefield T, Clark DJ, Andrianopoulos N, Brennan AL, Reid CM, Johns J, et al. Is there an obesity paradox after percutaneous coronary intervention in the contemporary era? An analysis from a multicenter Australian registry. JACC Cardiovasc Interven. 2010;3:660-8.

Key Words: transcatheter aortic valve implantation, aortic valve stenosis, obesity, body mass index, underweight 
TABLE E1. Proportion of missing data per body mass index category

\begin{tabular}{|c|c|c|c|c|c|c|}
\hline \multirow[b]{2}{*}{ Variable } & \multicolumn{6}{|c|}{ BMI category } \\
\hline & $\begin{array}{c}<18.5 \mathrm{~kg} / \mathrm{m}^{2} \\
(\mathrm{n}=205)\end{array}$ & $\begin{array}{c}18.5-24.9 \mathrm{~kg} / \mathrm{m}^{2} \\
(\mathrm{n}=3564)\end{array}$ & $\begin{array}{c}25-29.9 \mathrm{~kg} / \mathrm{m}^{2} \\
(\mathrm{n}=5460)\end{array}$ & $\begin{array}{c}30.0-34.9 \mathrm{~kg} / \mathrm{m}^{2} \\
(\mathrm{n}=2257)\end{array}$ & $\begin{array}{c}35-39.9 \mathrm{~kg} / \mathrm{m}^{2} \\
(\mathrm{n}=658)\end{array}$ & $\begin{array}{l}\geq 40 \mathrm{~kg} / \mathrm{m}^{2} \\
(\mathrm{n}=237)\end{array}$ \\
\hline \multicolumn{7}{|l|}{ Procedural } \\
\hline Conversion to open heart surgery & $3(1.3)$ & $200(5.6)$ & $636(11.6)$ & $194(8.6)$ & $28(4.3)$ & $6(3.3)$ \\
\hline \multicolumn{7}{|l|}{ During hospital admission } \\
\hline Mortality & $2(1.0)$ & $40(1.1)$ & 89 (1.6) & $55(2.4)$ & $13(2.0)$ & $6(3.3)$ \\
\hline Stroke & $0(0)$ & $29(0.8)$ & $87(1.5)$ & $61(2.7)$ & $18(2.3)$ & $2(2.9)$ \\
\hline Myocardial infarction & $18(8.8)$ & $227(6.4)$ & $310(5.7)$ & $133(5.9)$ & $29(4.4)$ & $11(4.6)$ \\
\hline Major or life-threatening bleeding & $18(8.8)$ & $361(10.1)$ & $496(9.1)$ & $193(8.6)$ & $58(8.8)$ & $18(7.6)$ \\
\hline New-onset atrial fibrillation & $55(26.8)$ & $1284(36.0)$ & $2427(44.4)$ & $1135(50.3)$ & $360(54.7)$ & $123(51.9)$ \\
\hline Permanent pacemaker implantation & $4(19.5)$ & $338(5.9)$ & $615(11.2)$ & $188(8.3)$ & $22(3.3)$ & $7(3.0)$ \\
\hline \multicolumn{7}{|l|}{ At $30 \mathrm{~d}$} \\
\hline Mortality & $18(8.8)$ & $296(8.3)$ & $521(9.5)$ & $215(9.6)$ & $16(10.4)$ & $23(9.7)$ \\
\hline Stroke & $18(8.8)$ & $297(8.3)$ & $528(9.7)$ & $216(9.6)$ & $16(10.4)$ & $23(9.7)$ \\
\hline \multicolumn{7}{|l|}{ At $1 \mathrm{y}$} \\
\hline Mortality & $62(30.2)$ & $1139(31.9)$ & $1984(36.3)$ & $790(35.0)$ & 209 (31.7) & $76(32.1)$ \\
\hline Stroke & $60(29.3)$ & $1097(30.8)$ & 1943 (35.5) & 781 (34.6) & 207 (31.4) & $76(32.1)$ \\
\hline
\end{tabular}

Values are presented as n (\%). BMI, Body mass index.

TABLE E2. Thirty-day mortality and stroke rates according to body mass index category in patients with balloon-expandable and self-expandable valves

\begin{tabular}{|c|c|c|c|c|c|c|}
\hline \multirow[b]{2}{*}{ Variable } & \multicolumn{6}{|c|}{ BMI category } \\
\hline & $\begin{array}{c}<18.5 \mathrm{~kg} / \mathrm{m}^{2} \\
(\mathrm{n}=205)\end{array}$ & $\begin{array}{c}18.5-24.9 \mathrm{~kg} / \mathrm{m}^{2} \\
(\mathrm{n}=3564)\end{array}$ & $\begin{array}{c}25-29.9 \mathrm{~kg} / \mathrm{m}^{2} \\
(\mathrm{n}=5460)\end{array}$ & $\begin{array}{c}30.0-34.9 \mathrm{~kg} / \mathrm{m}^{2} \\
(\mathrm{n}=2257)\end{array}$ & $\begin{array}{c}35-39.9 \mathrm{~kg} / \mathrm{m}^{2} \\
(\mathrm{n}=658)\end{array}$ & $\begin{array}{l}\geq 40 \mathrm{~kg} / \mathrm{m}^{2} \\
(\mathrm{n}=237)\end{array}$ \\
\hline \multicolumn{7}{|l|}{ Allocation } \\
\hline Balloon-expandable & $96(46.8)$ & $1851(51.9)$ & $2785(51.0)$ & 1099 (48.7) & $291(44.2)$ & $117(49.4)$ \\
\hline Self-expandable & $109(53.2)$ & $1713(48.1)$ & $2675(49.0)$ & $1158(51.3)$ & $367(55.8)$ & $120(50.6)$ \\
\hline \multicolumn{7}{|l|}{ 30-d mortality } \\
\hline Balloon-expandable & $9(10.6)$ & $115(7.0)$ & $118(4.8)$ & $39(4.1)$ & $17(7.0)$ & $8(7.7)$ \\
\hline Self-expandable & $10(9.7)$ & $111(6.9)$ & $137(5.5)$ & $55(5.1)$ & $22(6.3)$ & $8(7.3)$ \\
\hline$P$ value & .84 & .96 & .29 & .27 & .74 & .91 \\
\hline \multicolumn{7}{|l|}{ 30-d stroke } \\
\hline Balloon-expandable & $3(3.5)$ & 48 (2.9) & $58(2.4)$ & $17(1.8)$ & $7(2.9)$ & $7(2.9)$ \\
\hline Self-expandable & $2(2.0)$ & $48(3.0)$ & $67(2.7)$ & $26(2.4)$ & $9(2.6)$ & $2(1.8)$ \\
\hline$P$ value & .51 & .88 & .48 & .31 & .82 & .59 \\
\hline
\end{tabular}

Values are presented as $\mathrm{n}(\%) . B M I$, Body mass index. 